\title{
Should Microalbuminuria Ever Be Considered as a Renal Endpoint in Any Clinical Trial?
}

\author{
Debate \\ PRO Position \\ Lambers Heerspink, H.J.; de Zeeuw, D. (Groningen) \\ CON Position \\ Glassock, R.J. (Los Angeles, Calif.) \\ Rebuttal \\ PRO Position \\ de Zeeuw, D.; Lambers Heerspink, H.J. (Groningen) \\ CON Position \\ Glassock, R.J. (Los Angeles, Calif.)

\section{Editorial Perspective} \\ Weir, M.R. (Baltimore, Md.); Bakris, G.L. (Chicago, III.)
}

